\title{
A EDUCAÇAO DA PESSOA IDOSA UNIVERSITÁRIA E A PEDAGOGIA DE PAULO FREIRE
}

\author{
THE EDUCATION OF THE OLD AGE UNIVERSITY STUDENTS AND THE \\ PEDAGOGY OF PAULO FREIRE
}

\section{LA EDUCACIÓN DE LA PERSONA MAYOR UNIVERSITARIA Y LA PEDAGOGÍA DE PAULO FREIRE}

\author{
Valéria Carraro* \\ Mauro José Ferreira Cury
}

\begin{abstract}
Resumo: O objetivo deste artigo é tratar de um tema que contribua para o debate acerca da importância do idoso no atual cenário mundial e brasileiro; também se propõe a compreender o sentido da educação na vida do idoso, indivíduo que, após completar 60 anos ou mais, matricula-se num curso de graduação, em instituição de ensino regular e presencial e, durante dois, três, quatro ou mais anos, frequenta as aulas, realiza as atividades acadêmicas e convive em um ambiente com pessoas de diferentes idades/ gerações. Busca-se ampliar as informações sobre o envelhecimento com o intuito de contribuir para a atualização do conceito estabelecido no imaginário social do que é velhice. O suporte teórico está baseado no universo do educador Paulo Freire, tendo em vista a ideia de que a educação é libertadora e desafiadora e, para os idosos que ingressam na universidade, mesmo havendo inúmeros desafios decorrentes da idade, os benefícios da aprendizagem são evidentes, já que oportunizam as relações intergeracionais, aquisição de novos saberes e a possibilidade dos idosos vislumbrarem um recomeço de uma nova carreira, de se tornarem novos atores sociais ou, ainda, quem sabe, apenas aproveitarem o tempo para o ócio intelectual. Os desafios e benefícios da educação levarão ao envelhecimento ativo e à conquista da cidadania. Este artigo trata de uma pesquisa empírica, teórica, qualitativa de cunho bibliográfico, que busca nas teorias de Freire e Edgar Morin novas possibilidades conclusivas para a educação da pessoa idosa.
\end{abstract}

Palavras-chave: Idoso. Educação. Paulo Freire. Edgar Morin. Universidade.

\begin{abstract}
The aim of this article is to discuss a topic that contributes to the debate about the importance of the elderly in the current world and Brazilian scenario; it also intends to understand the meaning of education in the elderly's life, people who from turning 60 years old, enrolls in an undergraduate course of a regular and face-to-face teaching institution, attending two, three or more years of classes and performing academic activities and live in an environment with people of different ages and generations. It seeks to expand information on aging in order to contribute to update the concept of old age established in the social imaginary. The theoretical support is based on Paulo Freire's universe, considering the idea that education is liberating and challenging, and for the older adults who enter the university, even though there are innumerable challenges due to age, the benefits of learning are evident, since they allow for intergenerational relations, the acquisition of new knowledge and the possibility for the elderly to see a new career start, to become new social actors or, perhaps, to seize the
\end{abstract}

\footnotetext{
*Universidade Nove de Julho. E-mail: vacarraro@gmail.com

** Universidade do Oeste do Paraná - UNIOESTE. E-mail: maurojfc@gmail.com
} 
time for intellectual leisure. The challenges and benefits of education will lead to active aging and the achievement of citizenship. This article deals with an empirical, theoretical, qualitative literature review which searches in Freire and Edgar Morin's theories new conclusive possibilities for the education of elderly people.

Keywords: Elderly. Education. Paulo Freire. Edgar Morin. University.

Resumen: El propósito de este artículo es discutir acerca de la importancia de las personas mayores en el actual escenario mundial y brasileño; también se propone comprender el significado de la educación en la vida de las personas mayores que, después de cumplir 60 años o más, deciden inscribirse en un posgrado en una institución regular y presencial y, por dos, tres, cuatro o más años asiste a clases, realiza las actividades académicas y convive en un ambiente con personas de diferentes edades/ generaciones. El objetivo es ampliar la información sobre el envejecimiento para contribuir con la actualización del concepto establecido en el imaginario social de lo que es la vejez. El sustento teórico está basado en el universo del educador Paulo Freire, teniendo en mente la idea de que la educación es libertadora y desafiante y, para las personas mayores que están en la universidad, incluso con numerosos retos derivados de la edad, los beneficios del aprendizaje son evidentes, desde las relaciones intergeneracionales, adquisición de nuevos conocimientos y la capacidad de que los ancianos vislumbren la oportunidad de un nuevo comienzo de una carrera profesional, además de se convirtieren en nuevos actores sociales; o, quizá, para disfrutaren el tiempo con la pereza intelectual. Los retos y beneficios de la educación conducirán al envejecimiento activo y a conquista de la ciudadanía. Este artículo trata de una investigación empírica, búsqueda bibliográfica, teórica, cualitativa y está basado en las teorías de Paulo Freire y Egdar Morin acerca de la educación de las personas mayores.

Palabras-Clave: Persona Mayor. Educación. Paulo Freire. Edgar Morin. Universidad.

\section{Introdução}

Ao conhecer as interfaces dos estudos e pesquisas educacionais na trajetória de Paulo Freire, torna-se possível perceber algumas “picadas” deste caminho que se relacionam com o objeto desta pesquisa: o idoso universitário.

Ninguém caminha sem aprender a caminhar, sem aprender a fazer o caminho caminhando, refazendo e retocando o sonho pelo qual se pôs a caminhar. (FREIRE, 2002)

Este artigo tem o objetivo de apresentar uma reflexão sobre a educação da pessoa idosa, a pedagogia de Paulo Freire e associar as contribuições de Edgar Morin como uma perspectiva do repensar e construir uma nova educação para um Brasil que envelhece.

Trata-se de uma pesquisa empírica, teórica, qualitativa de cunho bibliográfico que busca, nas teorias de Freire e Morin, novas possibilidades conclusivas para a educação da pessoa idosa.

A partir do momento em que o idoso for considerado como um sujeito capaz de desenvolver atividades e desempenhar novos papéis sociais, será possível perceber uma mudança na visão ultrapassada que se tem sobre a velhice no Brasil, pois o idoso incapaz, inútil e improdutivo passará a ser um novo agente social e terá chances de renovar-se, por meio da educação, por exemplo, quando se propõe a ingressar na universidade, interagindo em novos espaços sociais e culturais e, principalmente, ao (re) definir sua identidade, será capaz de superar as dificuldades que lhe foram impostas durante a vida e que, muitas vezes, são acentuadas quando ingressa na terceira idade. 
Assim, a educação é um processo indispensável ao longo da vida, considerando-se que o homem é um ser inconcluso, de acordo com Paulo Freire, “[...] onde há vida, há inacabamento” (2002, p.55), e que continuamente está se desenvolvendo, crescendo, aprimorando. Desta forma, o processo de aprendizagem tem importância vital na velhice. Importância na superação de situações de vulnerabilidade com que se defrontam os idosos. O envelhecimento conduz a uma mudança significativa nos papéis sociais, que precisam de uma ressignificação tanto em nível micro, a família, como em nível macro, a sociedade. Monteiro (2015, p.27-34) considera:

[...] o envelhecimento é um processo contínuo de transformação do humano como ser único em seu tempo vivido; [...] envelhecer é sinônimo de viver; [...] viver é conhecer; [...] o viver humano constitui-se possibilidade de construção, desconstrução e reconstrução de configurações totalmente diferenciadas a cada instante em suas experiências formando o seu sentido histórico através do espaço relacional com o mundo e com os outros; [...] o velho precisa continuar sua caminhada permeado pelo amor, porque sua dinâmica biológica depende disso.

A educação brasileira historicamente se desenvolveu de forma arcaica e preconceituosa em relação ao idoso; somente com as Políticas Nacionais voltadas para o Idoso e a criação de Estatuto do Idoso (Lei N 10.741/03) é que a inserção da pessoa idosa brasileira se fez de forma inclusiva na sociedade.

A pedagogia de Paulo Freire (2005) traz uma contribuição importante para o entendimento da inserção do idoso na escola, ao afirmar que "A realidade social, objetiva, que não existe por acaso, mas como produto da ação dos homens, também não se transforma por acaso” (p.37). O autor complementa: “Se os homens são os produtores desta realidade e se esta, na “inversão da práxis”, se volta sobre eles e os condiciona, transformar a realidade opressora é tarefa histórica, é tarefa dos homens” (p.37).

O presente artigo está estruturado nas bases conceituais de valorização da educação sob a ótica do universo freiriano, aborda questões relacionadas à população idosa presente em um país (Brasil) que envelhece e finaliza com a pedagogia de Paulo Freire e com as possibilidades reflexivas educacionais do pensamento complexo de Edgar Morin.

\section{A educaçao para a pessoa idosa sob o olhar de Paulo Freire}

Na perspectiva do educador Paulo Freire, o processo educacional é um ato de libertação, que somente se concretizará através da comunhão entre o ensinante (professor) e o aprendiz (aluno). O conceito de tensão dialética aplica-se na sequência de ações que acontecem no processo de aprendizagem aprender, apreender, reaprender, incorporar, avançar - e é nesse processo que ocorrerá a construção do real, que exige uma ressignificação constante do papel desempenhado pelo professor que, antes de ensinar, aprende.

Importante ressaltar que existe diferença entre aprender e apreender, embora os dois verbos estabeleçam uma relação entre os sujeitos e o conhecimento. Apreender significa segurar, prender, pegar, assimilar mentalmente, entender, compreender, agarrar. Não se trata de um verbo passivo; para apreender é preciso agir, exercitar-se, informar-se, tomar para si, apropriar-se. O mesmo não acontece quando se usa o verbo aprender, que é um derivado de apreender por síncope, mas significa tomar conhecimento, reter na memória mediante estudo, receber uma informação. 
Assim sendo, neste artigo, a educação que se pretende alcançar refere-se à apropriação do conhecimento pelo aluno, que vai bem além do simples repasse da informação, é preciso superar o aprender, que se resume em um simples processo de memorização e partir em busca do apreender, segurar, apropriar, agarrar, prender, pegar, assimilar mentalmente, entender e compreender. O processo de apreensão está relacionado com o enredar, estabelecendo os nós necessários entre os fios a serem tecidos pelo ensinante e o aprendiz.

A maravilha do aprendizado está na incompletude do ser, que encontra no outro o seu diferente e, portanto, há que se respeitar sua cultura, seus valores e sua história para que juntos, em plena comunhão, as transformações aconteçam e o ensinante aprende enquanto o aprendiz ensina e vice-versa; essa maneira de ensinar e aprender, ensinar e compartilhar utopias, ensinar numa perspectiva humanística é um ensinar como um projeto de vida, em que há uma vivência verdadeira em que ocorre a mistura com as diferenças.

Como sujeitos da história, sempre atuamos na realidade a fim de modificá-la. Isso ocorre porque ao estar presente no mundo fazemos parte e o percebemos, assim passamos a entendê-lo e constatamos que não somos apenas objeto da História, mas seu sujeito igualmente; somos pessoas capazes de intervir na realidade de modo a gerar novos saberes e criativas soluções para os problemas presentes em nossa vida. Paulo Freire (2002, p.85-86) afirma que "No mundo da História, da cultura, da política, constato não para me adaptar, mas para mudar”.

“Mudar é difícil, mas é possível”. Para Paulo Freire é a partir desse saber fundamental que devemos, juntamente com os grupos populares, lutar contra a miséria, a violência e a profunda injustiça que caracterizam a situação dessas populações sofridas e espoliadas como os favelados. É, dessa forma, que a educação intervém no mundo trazendo alegria, esperança, respeito e sensibilização.

Na educação, alegria e esperança são valores imprescindíveis à prática. "Há uma relação entre a alegria necessária à atividade educativa e a esperança.” (FREIRE, 2002, p.80). A esperança é fundamental à experiência humana; professor e aluno precisam estar sempre esperançosos de que juntos resistirão aos obstáculos e crescerão continuamente. Isso implica o inacabamento do ser que, consciente disso, está constantemente envolvido num processo de busca.

Paulo Freire (2002) afirma que “[...] o inacabamento do ser ou sua inconclusão é própria da experiência vital. Onde há vida, há inacabamento" (p.55). Dizer que o aluno é um ser inacabado significa reconhecer que ele está em contínua fase de construção, num permanente processo de busca, pois esta inconclusão é própria do ser humano e consiste na expressão da autonomia, na liberdade que ele tem de ser curioso, instigador e crítico. É ela que nos torna protagonistas de nossa história, diferentes dos outros seres, de modo a intervir no mundo lutando para "não ser apenas objeto, mas sujeito também da História” (FREIRE, 2002, p.60). Significa dizer que a inconclusão é própria da essência da vida e jamais se extingue enquanto movimento próprio da «energia vital».

O ser humano está em constantes transformações, como um ser histórico que é, vive em uma condição de incompletude. A educação é transformadora e torna-se um meio muito eficaz para chegarmos à «finitude da infinitude”. Educação é um caminho que dá a possibilidade ao homem de experimentar-se, arriscar-se, aprender e encontrar novas trajetórias de caminhar ou até traçar um caminho diferente. 
A educação é uma resposta da finitude da infinitude. A educação é possível para o homem, porque este é inacabado e sabe-se inacabado. Isto o leva a sua perfeição. A educação, portanto, implica uma busca realizada por um sujeito que é o homem. O homem deve ser o sujeito de sua própria educação. Não pode ser o objeto dela. Por isso ninguém educa ninguém (FREIRE, 1982, p.27).

A noção de educação deve nos remeter ao entendimento freireano de que o ser humano é, por sua "natureza”, inacabado e ele tem consciência de sua inconclusão. Ou seja, “Onde há vida, há inacabamento. Mas só entre mulheres e homens o inacabamento se tornou consciente" (2002, p.55). Assim, a educação adquire o elevado propósito que é o de criar condições para que o ser humano possa desenvolver sua criticidade e problematizar conscientemente seu inacabamento que é uma fonte inesgotável de descobertas e possibilidades, portanto, um devenir que jamais se estanca pelo movimento mesmo da dinâmica ontológica do real que o configura e que se realiza através dos processos históricos e mediação com o mundo. Nisto também reside a esperança ontologicamente constituinte do humano, exatamente porque o humano, enquanto inconcluso, é pleno de possibilidades.

A esperança participa ativamente da dinâmica do real porque é no movimento do próprio real que o possível se realiza. Há uma busca constante do ser humano pelo resgate de características que contribuem para a construção de autoestima no sentido de atualizar-se para sentir-se integrado nos agrupamentos sociais em que esteja inserido.

Nesse âmbito, é imprescindível compreender de modo mais pontual a presença do idoso na sala de aula universitária comumente frequentada por jovens, contribuindo para a formação heterogênea do ambiente referido, pois segundo Lacerda (2000) este cenário é uma espécie de "caleidoscópio, no qual cada peça é importante para garantir a beleza e a riqueza do todo, ou seja, é desejável que na classe regular haja todo tipo de aluno para que o grupo se enriqueça” (p. 71).

\section{A populaçao idosa de um Brasil que envelhece}

O envelhecimento ativo, hoje, revela-se como uma das propostas sociais mais bem estruturadas para o público idoso, visando à integração social, por meio da inserção em diferentes espaços, além do reconhecimento político deste segmento. Os idosos ativos, enquanto atores sociais, representam uma das mais importantes forças sociais que começam a se organizar nesta década. Alguns dados são fundamentais para compreender a presença cada vez mais significativa de idosos nas salas de aula de uma universidade.

É notório o crescimento da população idosa brasileira. De acordo com dados do Instituto Brasileiro de Geografia e Estatística (IBGE - 2010), o país tinha 21 milhões de pessoas com idade igual ou superior a 60 anos em 2012. A estimativa da Organização Mundial da Saúde (OMS) é que o país seja o sexto em número de idosos em 2025, quando deve chegar a 32 milhões de pessoas com 60 anos ou mais.

O envelhecimento populacional é um proeminente fenômeno mundial. No Brasil este fato pode ser exemplificado pelo aumento da participação da população maior de 60 anos no total da população nacional: passou de 4\% em 1940 para 8,6\% em 2001. Nos últimos 60 anos, aumentou nove vezes o número absoluto de pessoas com mais de 60 anos. Projeta-se para 2020, no Brasil, um contingente de aproximadamente 30,9 
milhões de pessoas que terão mais de 60 anos (BELTRÃO; CAMARANO; KANSO, 2004).

A análise do cenário nacional, apresentado na Tabela 1, segundo dados do IBGE (2010), indica que cerca de 20,6 milhões de brasileiros são idosos (10.79\% da população). Segundo a Organização Mundial de Saúde, considera-se idoso o indivíduo a partir de 60 anos $^{1}$, conforme prescreve o Estatuto do Idoso, Lei 10.741/03. Esta idade refere-se aos países em desenvolvimento, como é o caso do Brasil; em países desenvolvidos, as pessoas são consideradas idosas a partir dos 65 anos.

Tabela 1: População Idosa (mais de 60 anos) 2000/2010

\begin{tabular}{l|l|l|l|l}
\hline \multirow{2}{*}{$\begin{array}{l}\text { Brasil } \\
\text { e U.F }\end{array}$} & \multicolumn{2}{|l|}{ População hab. } & \multicolumn{2}{c}{ População \% } \\
\cline { 2 - 5 } & 2000 & 2010 & 2000 & 2010 \\
\hline Brasil & 14.538 .987 & 20.588 .890 & 4,82 & 10,62 \\
\hline
\end{tabular}

IBGE: 2000 e 2010

O atual contexto socioeconômico possibilita que as pessoas, com mais idade e experientes, ultrapassem a linha do horizonte em relação ao futuro. Seja por questões meramente de ordem financeira ou por sentirem-se jovens aos 60, 70 anos, os idosos estão mostrando-se com mais energia, disposição e o principal: com a determinação para continuarem a aprender e ampliarem seus conhecimentos (CAMARANO, 2004). ${ }^{1}$

A expectativa de vida também tende a crescer, devendo chegar a 80 anos em 2041. A expectativa média é de 74,8 anos para bebês nascidos em 2013, segundo o IBGE. Com o envelhecimento dos cidadãos, o funcionamento das políticas públicas se torna essencial para a garantia dos direitos básicos do idoso. A população brasileira envelhece de modo acelerado,

\footnotetext{
${ }^{1}$ Como idoso, está se considerando a população de 60 anos e mais, tal como estabelecido na Política Nacional do Idoso.
}

e as pessoas com mais de 65 anos serão mais de um quarto dos brasileiros em 2060, segundo projeção do IBGE. O percentual desse grupo representa $7,4 \%$ do total de pessoas que vivem no país neste ano. $\mathrm{O}$ instituto atribui o aumento do número de idosos ao aumento da expectativa de vida e à queda da taxa de natalidade, já que as mulheres têm cada vez menos filhos. "Projeta-se uma manutenção da queda da mortalidade, que vem ocorrendo de forma contínua desde a primeira metade do século 20", afirma o IBGE, ao justificar sua previsão. Graças às melhores condições de saúde, à redução da mortalidade infantil e ao melhor acesso a serviços básicos, a esperança de vida também avançará de modo constante, segundo $\mathrm{o}$ instituto.

A expectativa de vida ao nascer atingiu 71,2 anos para homens e 78,5 para mulheres em 2013, de acordo com a projeção do IBGE. Em 2060, esses valores serão 78 para homens e 84,4 anos para as mulheres. Tratase, portanto, de um ganho de 6,8 anos de vida para os homens e 5,9 anos para as mulheres, respectivamente.

Diante dos dados apresentados, temas como velhice e processo de envelhecimento são relevantes para o desenvolvimento do conhecimento e desafiam os estudiosos e a sociedade brasileira. É fato consumado que o envelhecimento da população aconteça de maneira rápida e o Brasil ainda não equacionou a importância desta situação do idoso e de suas necessidades, o que reflete a pouca prioridade atribuída a esta população.

\section{Da pedagogia de Paulo Freire às possibilidades reflexivas educacionais do pensamento complexo de Edgar Morin}

Nesse cenário que se apresenta, a educação assume papel de destaque. Paulo 
Freire (2005) afirma que "seria uma violência que os homens, seres históricos e inseridos num movimento de busca com os outros homens, não fossem sujeitos de seu próprio movimento" (p.86). Sendo a educação um processo constante em todas as sociedades e responsável pela formação de seus membros à sua imagem e em função de seus interesses, também possui um caráter de transformação, independente da idade. Portanto, é preciso debater o tema do envelhecimento em todos os espaços possíveis, pois somente a mobilização permanente da sociedade será capaz de configurar um novo olhar sobre o processo de envelhecimento dos cidadãos brasileiros.

As instituições de ensino, entre as quais as universidades, precisam romper seus muros e diminuir a distância que existe com a sociedade, oportunizando conhecimentos aos idosos. A educação para o envelhecimento deve ser preconizada dentro de condições socioeconômicas e culturais, com seguridade social adequada para a manutenção de uma vida digna e produtiva na velhice. A partir do momento em que o idoso é considerado um sujeito capaz de desenvolver atividades e desempenhar novos papéis sociais, percebe-se que a visão sobre a velhice começa a ser modificada, pois o idoso incapaz e sem utilidade passa a ser um novo agente social. "Gradualmente, a visão de idosos como um subgrupo populacional vulnerável e dependente foi sendo substituída pela de um segmento populacional ativo e atuante que deve ser incorporado na busca do bem-estar de toda a sociedade" (CAMARANO, 2004, p.257-258).

É curioso perceber que um contingente de idosos procura as tradicionais Instituições de Ensino Superior com objetivos relacionados ou à sequência de sua formação profissional ou à realização de sonhos ligados àquela profissão de escolha, na qual, em outro período etário de sua vida, não foi possível efetivar. $O$ fato de inserirem-se em um contexto de sala de aula composto na maioria por jovens parece não assustá-los, ao contrário, a impressão que se tem é que nesse ambiente jovem, o idoso pode se revigorar ainda mais e, por outro lado, os jovens também têm muito a ganhar com a experiência de vida que os idosos oferecem.

Trilhando as veredas do pensamento complexo é possível perceber a própria incompletude do homem, dialoga-se com o irracionalizado e o irracionalizável, enfrenta-se a complexidade (o inseparável, o incerto e, justamente, o irracionalizável), afirma Morin (1995, p.183). Ao refletir sobre o aleatório, a incerteza, o inacabamento, o autor conclui que falar do incerto só faz sentido na inseparável implicação com o que se tem descoberto como certo, por detrás de tudo, o “indizível e o inconcebível”: "Sob os conceitos, existe o mundo, sob o mundo?...” (MORIN, 1995, p.222). Ainda acrescenta:

O real é mistério, mistério nos dois sentidos: no primeiro sentido é desconhecido/ incognoscível; no segundo sentido é uma cerimônia profana/sagrada onde as nossas vidas jogam e se jogam. Mas quem somos nós, homines sapientes dementes? Estamos na extremidade de uma asa cósmica, empurrados na e por uma aventura que nos ultrapassa. Estamos possuídos pelos mitos, pelos deuses, pelas ideias. Somos quase totalmente sonâmbulos. O nosso pensamento só ganha vida à temperatura da sua própria destruição. Todo o segredo do mundo está em nós, mas ignoramo-lo e ele é incompreensível: é talvez o mistério do mistério. As explicações míticas, religiosas racionalistas ocultam-nos o inexplicável que, no entanto, trazem em si. A ciência, que crê tudo esclarecer, cega. Ora, a verdadeira ciência é a que chega ao conhecimento da ignorância (MORIN, 1995, p.226).

Para Morin (1995), a complexidade não é tudo ou a totalidade do real, “mas é o 
que melhor pode abrir-se ao inteligível e ao mesmo tempo revelar o inexplicável” (p.227). A complexidade não acaba com a perplexidade, com o espanto e não destrói o sentimento do mistério: "Estou cercado pelo mistério. Tenho o sentimento de caminhar nas trevas, rodeado por galáxias de pirilampos que me escondem e revelam a obscuridade da noite" (MORIN, 1995, p.227). Não há um caminho que irá permitir ao homem sair das contradições que a vida moderna impõe; o que há para os seres humanos é um caminho certeiro que os coloca cada vez mais no "olho do furacão”, no centro dessas contradições.

A educação para os idosos constitui, portanto, um dos desafios para a sociedade brasileira face ao significativo e crescente número de idosos existentes no país. Conforme Severino (1994), “a educação deve ser vista como mediação para a construção da cidadania, uma educação politizada do povo, ou educação para o exercício da cidadania” (p.100). Independente da idade, o ser humano traz consigo a plenitude da vida. Na concepção deweyana (1971), na relação entre educação e vida há um processo natural em que a finalidade é a própria manutenção. Assim, a finalidade da educação é a busca de mais vida.

\section{Referências}

BELTRÃO, K. I. CAMARANO, A. A.; KANSO, S. Dinâmica populacional brasileira na virada do século $\mathrm{XX}$. Rio de Janeiro: IPEA, 2004.

CAMARANO. A. A. Os novos idosos brasileiros: muito além dos 60? Rio de Janeiro: IPEA, 2004.

DEWEY, J. Vida e educação. São Paulo: Melhoramentos, 1971.

FOLHA DE SÃO PAULO. Disponível: h t t p : / / w w w 1.folha.uol.com.br/ cotidiano/2013/08/1333690-idosos-serao14-da-populacao-no-ano-de-2060-aponta-oibge.shtml Acesso em 19-11-2014.

FREIRE, P. Educação para mudança. Rio de Janeiro, Paz e Terra, 1982.

Pedagogia da autonomia: saberes necessários à prática educativa. $21^{\text {a }}$ EdiçãoSão Paulo. Editora Paz e Terra, 2002.

.Pedagogia do Oprimido. Rio de Janeiro: Paz e Terra, 2005.

LACERDA, C. B. F. de. A prática pedagógica mediada (também) pela língua de sinais: trabalhando com sujeitos surdos. Cad. CEDES, Campinas, v. 20, n. 50, Apr.2000. DOI: 10.1590/S0101-32622000000100006. Disponível:http://www.scielo.br/scielo. php?script=sci_arttext\&pid=S01013262200 0000100006\&lng=en\&nrm=iso. Acesso em $18 / 05 / 2010$.

MONTEIRO, P. P. Envelhecer: histórias, encontros, transformações. Belo Horizonte: Autêntica, 2005.

MORIN, E. Os meus demônios. Mem Martins, Publicações Europa-América, 1995.

O POVO. Disponível:http://www.opovo. com.br/app/opovo/cotidiano/2013/09/28/ noticiasjornalcotidiano,3137628/brasil-tera32-milhoes-de-idosos-aponta-estudo-doibge.shtm

Acesso em 19-11-2014.

SEVERINO, A. J. A Metodologia do trabalho científico. São Paulo: Cortez. 2007. 